\title{
KELURAHAN GUNUNG ANYAR RAMAH ANAK BERKEBUTUHAN KHUSUS
}

\section{(GUNUNG ANYAR CHILDREN FRIENDLY SPECIAL NEEDS)}

\author{
Retno Indarwati ${ }^{1}$, Silvia Dwi Wahyuni ${ }^{2}$, Rista Fauziningtyas ${ }^{3}$ \\ Fakultas Keperawatan, Universitas Airlangga \\ e-mail: retno-i@fkp.unair.ac.id
}

\begin{abstract}
abtract
Persons with disabilities in Indonesia still experience negative stigma in society. Children with special needs are seen as burdensome, troublesome, embarrassing and useless. Because parents are embarrassed, the child is hidden sometimes the child is not schooled. The cause of these social problems is because the community does not understand about children with special needs. Efforts made to overcome these problems are education about children with special needs to cadres and motivation to parents. Cadres are social workers who are expected to be able to provide socialization to local residents. The second effort carries out motivation for $\mathrm{ABK}$ parents to be able to provide the best care for their children. The family is the first and foremost place in children's education. Care of children with special needs that are difficult is a burden for families. Support for the family aims to keep the family excited, able to go through difficult stages and not lose motivation in raising children with special needs. Purchasing educational toys to stimulate the growth and development of children with special needs.
\end{abstract}

Keywords: Cadres, Children with Special Needs, Parents

\section{abstrak}

Penyandang disabilitas di Indonesia masih mengalami stigma negatif di masyarakat. Anak berkebutuhan khusus dianggap sebagai beban, merepotkan, memalukan dan tidak berguna. Karena orang tua malu maka anak disembunyikan kadang anak tidak disekolahkan. Penyebab permasalahan sosial tersebut karena masyarakat tidak paham tentang anak berkebutuhan khusus. Upaya yang dilakukan untuk mengatasi masalah tersebut adalah edukasi tentang anak berkebutuhan khusus kepada kader dan motivasi kepada orang tua. Kader merupakan tenaga sosial yang diharapkan mampu memberi sosialisasi kepada warga sekitar. Upaya yang kedua melaksanakan motivasi kepada orang tua ABK agar mampu memberikan perawatan terbaik untuk anaknya. Keluarga merupakan tempat pertama dan utama dalam pendidikan anak. Perawatan anak berkebutuhan khusus yang sulit merupakan beban tersendiri bagi keluarga. Dukungan kepada keluarga bertujuan agar keluarga tetap bersemangat, mampu melewati tahaptahap sulit dan tidak kehilangan motivasi dalam membesarkan anak berkebutuhan khusus. Pembelian alat permainan edukatif untuk menstimulasi pertumbuhan dan perkembangan anak berkebutuhan khusus.

Kata kunci: Anak Berkebutuhan Khusus, Kader, Orang tua

\section{PENDAHULUAN}

Anak berkebutuhan khusus (ABK) adalah anak yang dianggap mempunyai kelainan dari kondisi rata-rata anak normal umumnya, dalam hal fisik, mental maupun karakteristik perilaku sosialnya (Efendi,2006). Berdasarkan Susenas Triwulan 1 Maret 2011, jumlah anak Indonesia sebanyak 82.980.000. Dari populasi tersebut, 9.957.600 anak adalah anak berkebutuhan khusus dalam kategori penyandang disabilitas. 
Di Kelurahan Gunung Anyar terdapat seorang ABK yang berusia 20 tahun tapi tidak bisa baca tulis dan tidak mengenal uang. Hal ini disebabkan orang tua hanya pasrah dengan kondisinya dan tidak melakukan upaya pembelajaran bagi ABK. Anak-anak yang memiliki disabilitas memiliki kecenderungan empat kali lebih besar dibanding anak normal untuk menerima kekerasan (Jones et all, 2012). Perundungan (bullying) terhadap anak dengan autism sering terjadi, sebesar $46 \%$ remaja dengan autisme menerima perundungan setidaknya sekali dalam sebulan, sementara $27 \%$ dari mereka bahkan menerima perundungan lebih dari sekali dalam seminggu (Van Roekel, 2010). Sekitar bulan Desember 2017 di Kelurahan Gunung Anyar terjadi kasus seorang remaja tuna grahita dituduh mencuri dan ditahan.

Penyebab permasalahan sosial tersebut karena masyarakat tidak paham tentang anak berkebutuhan khusus. Masyarakat yang tidak tahu tentang anak berkebutuhan khusus cenderung tidak perduli, diskriminasi sehingga stigma terhadap ABK masih terjadi di masyarakat. Potensi yang ada di Kelurahan Gunung Anyar adalah terdapat sanggar bermain bagi anak berkebutuhan khusus. Sanggar Anak Cerdas baru beroperasi sekitar 3 bulan. Sanggar ini bisa sebagai pusat informasi tentang anak berkebutuhan khusus sehingga masyarakat Kelurahan Gunung Anyar mudah dalam mengakses pelayanan.

Tanggapan masyarakat terhadap anak berkebutuhan khusus masih beragam. Masyarakat mempunyai anggapan bahwa anak berkebutuhan khusus merupakan anak yang aneh sehingga ketika mereka bertemu dengan anak tersebut akan menjauhinya. Hal ini menyebabkan keluarga yang memiliki anak berkebutuhan khusus merasa malu untuk membawa mereka keluar rumah. Tetapi ada juga keluarga yang memiliki anak berkebutuhan khusus kurang perduli terhadap perkembangan anaknya. Keluarga yang mempunyai anak berkebutuhan khusus mempunyai tantangan yang cukup berat dalam perawatan sehari-hari. Banyak kesulitan yang dialami keluarga misalnya ketika pertama kali dihadapkan pada kenyataan bahwa anak mereka tidak seperti anak pada umumnya. Keluarga kecewa, terpukul dan tidak bisa menerima diagnosa anaknya. Kesulitan lain yang dihadapi adalah keluarga harus mengasuh dan mendidik anak yang memiliki keterbatasan kemampuan dalam berbagai area komunikasi, sensori atau intelektual. Masalah finansial juga dialami keluarga karena anak-anak berkebutuhan khusus membutuhkan penanganan kesehatan, sosial dan pelayanan pendidikan khusus yang jumlahnya besar. Pengasuhan anak berkebutuhan khusus membutuhkan perhatian dan penanganan lebih karena dapat menimbulkan stress secara fisik maupun psikis pada keluarga.

\section{METODE PENGABDIAN MASYARAKAT}

Kegiatan pengabdian masyarakat yang dilaksanakan meliputi 2 kegiatan yaitu pelatihan identifikasi anak berkebutuhan khusus dan motivasi pada orang tua ABK. Sasaran pada pengabdian masyarakat yang pertama adalah kader, sedangkan pada pengabdian masyarakat kedua adalah orang tua. Persiapan yang dilakukan adalah koordinasi dengan pihak Kelurahan Gunung Anyar untuk menentukan jadwal kegiatan. Pelatihan kader dilaksanakan pada tanggal 13 September 2018 jam 09.00 - 12.00 di Kelurahan Gunung Anyar. Pelatihan ini dilakukan dengan memberikan materi tentang anak berkebutuhan khusus lalu kader diundang pada acara motivasi sehingga kader bisa berinteraksi dengan ABK dan melihat penampilannya. Kegitan kedua adalah pemberian motivasi pada keluarga dengan anak berkebutuhan khusus. Acara ini juga didesain dengan adanya 
penampilan $\mathrm{ABK}$ untuk memberikan kesempatan mereka untuk berani tampil di depan umum. Tujuan dari kegiatan ini adalah memelihara motivasi keluarga agar dapat menerima kondisi dan tetap semangat dalam merawat anaknya.

\section{HASIL DAN PEMBAHASAN}

Anak Berkebutuhan Khusus merupakan anak yang dalam proses pertumbuhan atau perkembanganya mengalami kelainan atau penyimpangan dalam hal fisik, mental intelektual, sosial, atau emosional dibandingkan dengan anak-anak seusianya. ABK masuk dalam daftar kelompok anak yang rentan mengalami kekerasan. Bentuk-bentuk kekerasan yang rentan dialami pun sangat beragam, seperti kekerasan fisik, psikis, hingga hambatan-hambatan sosial seperti pelabelan negatif dan diskriminasi. Keluarga merupakan lingkungan pertama dan utama dalam proses tumbuh kembang anak. Memiliki anak berkebutuhan khusus mempengaruhi ibu, ayah, dan semua anggota keluarga dengan cara yang bervariasi. Rentang dan dinamika emosi yang terjadi juga bermacam- macam (Hardman, dkk, 2002). Orang tua disamping harus menghadapi dinamika psikologis mereka sendiri juga harus menghadapi berbagai tuntutan eksternal. Menghadapi respons masyarakat bukanlah hal yang mudah bagi orang tua dari anak berkebutuhan khusus.

Pandangan negatif di masyarakat disebabkan pemahaman masyarakat terhadap anak berkebutuhan khusus yang rendah. Tanggapan masyarakat terhadap anak berkebutuhan khusus masih beragam. Masyarakat mempunyai anggapan bahwa anak berkebutuhan khusus merupakan anak yang aneh sehingga ketika mereka bertemu dengan anak tersebut akan menjauhinya. Hal ini menyebabkan keluarga yang memiliki anak berkebutuhan khusus merasa malu untuk membawa mereka keluar rumah atau keluarga kurang perduli terhadap perkembangan anaknya.

Keluarga yang mampu menghadapi masa-masa sulit yang akhirnya mampu bertahan dan beradaptasi dengan sukses hingga menjadi sebuah keluarga yang resilien. Masyarakat yang perduli, mau memberikan bantuan akan sangat membantu keluarga. Tersedianya dukungan sosial untuk mereka yang tengah mengalami krisis secara umum akan meningkatkan kesejahteraan psikologis dan kualitas kehidupan keluarga. Keluarga tidak boleh kehilangan motivasi dalam membesarkan anak berkebutuhan khusus. Di balik kekurangan yang dimiliki, anak berkebutuhan khusus masih memiliki sejumlah kemampuan untuk membantu dirinya. Dukungan keluarga akan meningkatkan kepercayaan diri pada anak untuk menggali potensi yang dimiliki karena membangun masa depan anak berkebutuhan khusus dimulai dari keluarga.
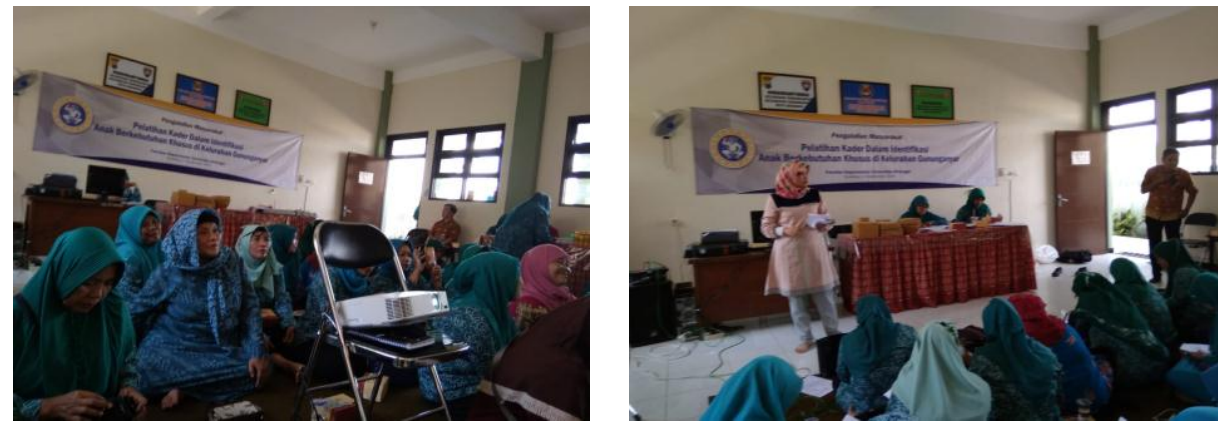

Gambar 1. Pemberian materi pelatihan dan motivasi 

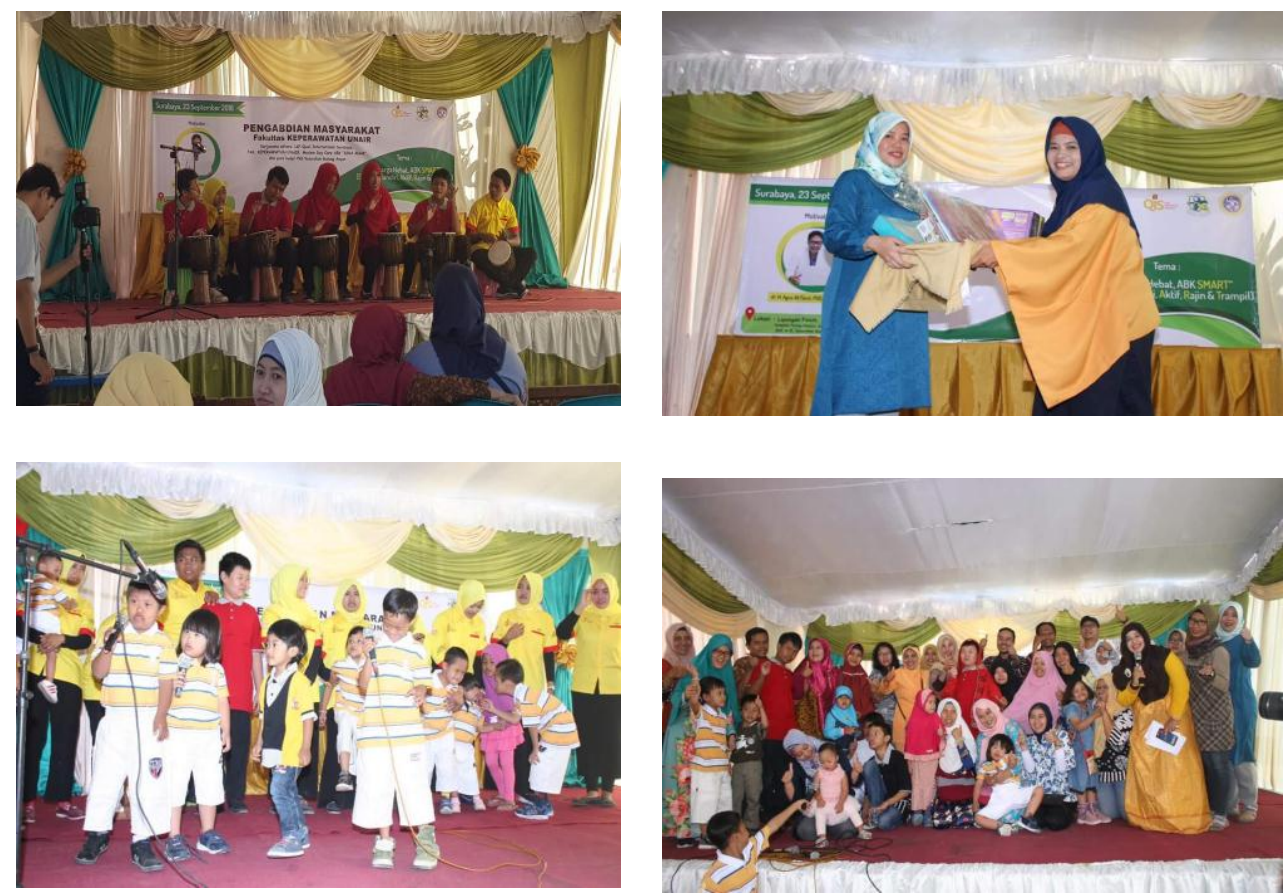

Gambar 2. Apresiasi ABK melalui kesenian serta penyerahan cinderamata

\section{PENUTUP}

\section{Smpulan dan Saran}

Keluarga yang mempunyai ABK harus mampu menerima segala keterbatasan yang dimiliki anaknya dan memberikan dukungan penuh untuk perkembangannya. Orang tua hendaknya tidak pernah berhenti untuk menggali informasi sebanyak-banyaknya tentang ABK sehingga dapat memberikan pengasuhan yang tepat.

Masyarakat dapat membantu dengan tidak memberikan pandangan takut terhadap ABK atau sekadar tidak menjadikan mereka bahan gunjingan atau tontonan karena hal tersebut sudah cukup menyakitkan bagi ABK ataupun orang tua mereka. Edukasi pada masyarakat melalui kader berguna untuk meningkatkan kepedulian dan penemuan kasus secara dini sehingga ABK bisa mendapatkan intervensi sejak awal. Marilah kita buat lingkungan yang nyaman untuk ABK dengan peduli keberadaan mereka. Dukungan berbagai pihak sangat membantu bagi kepercayaan diri anak berkebutuhan khusus untuk dapat bekarya dan menggapai cita-citanya.

\section{DAFTAR PUSTAKA}

Efendi, Muhammad. 2006. Psikopedagogik Anak Berkelainan. Jakarta: Bumi Aksara

Hardman, M.L., Drew, C.J., and Egan, M.W. 2002. Human Exceptionality. Boston: Allyn and Bacon, A Pearson Education Company 
Jones, Lisa et al. "Prevalence and risk of violence against children with disabilities: a systematic review and meta-analysis of observational studies." Lancet (London, England) vol. 380,9845 (2012): 899-907. doi:10.1016/S01406736(12)60692-8

van Roekel, Eeske et al. "Bullying among adolescents with autism spectrum disorders: prevalence and perception." Journal of autism and developmental disorders vol. 40,1 (2010): 63-73. doi:10.1007/s 10803-009-0832-2 